\title{
Regulation of Melanotropin Release from the Pars Intermedia of the Amphibian Xenopus laevis: Evaluation of the Involvement of Serotonergic, Cholinergic, or Adrenergic Receptor Mechanisms
}

\author{
B. M. Lidy Verburg-Van Kemenade, Bruce G. Jenks, and A. P. VAN Overbeeke
}

\author{
Department of Zoology, Faculty of Science, Catholic University, Toernooiveld, \\ 6525 ED Nijmegen, The Netherlands
}

Accepted April 15, 1986

\begin{abstract}
Melanophore-stimulating hormone (MSH) release from the pars intermedia of the pituitary gland is probably regulated by multiple factors of hypothalamic origin. We have examined a number of potential regulatory factors for their effects on MSH release from the amphibian Xenopus laevis. Serotonin and acetylcholine have no effect on MSH release. Both adrenaline and noradrenaline inhibit release of MSH in a dose-dependent manner. Studies with specific receptor agonists and antagonists reveal that these neurotransmitters exert their in vitro effects primarily through a dopamine D-2 receptor, although an $\alpha$-adrenergic receptor could not be excluded. We further conclude that the pars intermedia of $X$. laevis lacks a $\beta$-adrenergic receptor for the regulation of $\mathrm{MSH}$ secretion from the pars intermedia. In mammals, this receptor activates the adenylate cyclase system. Our studies reveal that despite the lack of $\beta$-adrenergic receptors, cyclic-AMP is likely an intracellular factor involved in the stimulation of MSH release. (c) 1986 Academic Press, Inc.
\end{abstract}

Melanophore-stimulating hormone (MSH), released from the pars intermedia of the pituitary gland, controls pigment dispersion in dermal melanophores during background adaptation of amphibians. The release of this hormone is regulated by factors of hypothalamic origin which are thought to be released from nerves terminating in the neurointermediate lobe. Hypothalamic regulation is believed to be mainly inhibitory. Dopamine is thought to be a very important neurotransmitter in this regard (Davis and Hadley,' 1978; Jenks, 1977; Terlou et al., 1974), and in at least one amphibian species (Verburg-van Kemenade et al., 1986) the neurotransmitter GABA is likely involved. Other classical neurotransmitters have also been implicated in the regulation of melanotropin release. The indolamine serotonin has been reported to stimulate release from melanotropes of lower vertebrates (Thornton and Geschwind, 1975) and a cholinergic mechanism has been suggested for stimulation of the pars intermedia of an amphibian species
(Hadley et al., 1976; Dierst-Davis et al., 1966). In mammals, a $\beta$-adrenergic mechanism for stimulation of melanotropin secretion is well established (Cote et al., 1980; Tilders et al., 1981). Stimulation of this $\beta$ receptor activates the adenylate cyclase system, thus increasing intracellular levels of cyclic-AMP (cAMP), which leads to elevated release of MSH (Cote et al., 1980; Munemura et al., 1980). For amphibians, the initial indication of $\beta$-adrenergic stimulation of MSH secretion from Rana pipiens (Bower et al., 1974) has recently been extended to a second amphibian species. Rana ridibunda (Tonon et al., 1983). In the aquatic toad Xenopus laevis, the $\beta$-adrenergic receptor agonist isoproterenol has been reported to inhibit the release of MSH and other peptides derived from the common prohormone pro-opiomelanocortin (Loh and Gainer, 1977). This observation appears to be in agreement with a report that CAMP inhibits MSH release in this species (Loh et al., 1981), although it has earlier been reported that cAMP is ex- 
tremely potent in stimulating release of MSH from Xenopus neurointermediate lobes (Jenks, 1977). In addition to the $\beta$-adrenergic receptor, the presence of $\alpha$-adrenergic receptors on melanotropes of both an amphibian (Bower et al., 1974) and a mammalian species (Jackson and Lowry, 1983) has been proposed. In both cases this receptor is reported to be involved in inhibition of MSH release. We have undertaken a study to evaluate the possible involvement of various neurotransmitters in the control of MSH release from the pars intermedia of $X$. laevis. This study was accomplished through the analysis of release of immunoreactive melanotropin from superfused neurointermediate lobes. By using specific receptor agonists and antagonists, an attempt was made to characterize the receptor mechanisms involved. As the physiological state of the animal (i.e., white- or black-background-adapted) may have some influence on melanotrope sensitivity to secretagogues, we tested each potential secretagogue on neurointermediate lobes of both white- and black-background-adapted animals.

\section{MATERIALS AND METHODS}

Animals. X. laevis were bred and reared in our acquatic facility. Animals were adapted to black or white background in black or white containers under constant illumination at $22^{\circ}$. Degree of pigment dispersion in dermal melanophores was determined by measurement of the melanophore index according to Hogben and Slome (1931).

In vitro superfusion experiments. Details concerning our method of superfusion of neurointermediate lobes are given elsewhere (Verburg-van Kemenade $e t$ al., 1986). Briefly, superfusion was performed using small perifusion chambers $(10 \mu \mathrm{l})$, each containing an individual lobe. The incubation medium contained $112 \mathrm{~m} M \mathrm{NaCl}, 2 \mathrm{~m} M \mathrm{KCl}, 2 \mathrm{~m} M \mathrm{CaCl}_{2}, 15$ $\mathrm{m} M$ Hepes, pH 7.38, $0.3 \mathrm{mg} / \mathrm{ml} \mathrm{BSA}, 2 \mathrm{mg} / \mathrm{ml}$ glucose. Medium was pumped through each chamber (1.5 $\mathrm{ml} / \mathrm{hr}$ ) and fractions of $7.5 \mathrm{~min}$ were collected. Fractions were stored frozen $\left(-20^{\circ}\right)$ before submitting them to radioimmunoassay for MSH determinations. As described earlier (Verburg-van Kemenade et al., 1986), within an experiment the results of those lobes showing similar baseline patterns of release were grouped, percentage basal release was calculated for each lobe within the group, and these values were then averaged. Neurotransmitters, or their specific agonists or antagonists, were administered at various time periods during the superfusion. The following products were tested either individually or in various combinations: the neurotransmitters serotonin, acetylcholine, adrenaline, and noradrenaline; the $\alpha$-adrenergic receptor agonist phenylephrine and its antagonist phentolamine; the $\beta$-adrencrgic receptor agonist isoproterenol and its antagonist propranolol; and the dopamine D-2 receptor antagonist sulpiride (all purchased from Sigma). Several experiments were conducted using the cyclic-AMP analog 8-bromo-adenosine 3',5'-monophosphate (8-Br-cAMP, Sigma).

Radioimmunoassay. The MSH concentration in the effluent was quantified by radioimmunoassay, using an antiserum produced and characterized by Vaudry et al. (1978). It shows equal cross-reactivity to desacetyl- $\alpha$-MSH and $\alpha$-MSH. Immunobound and unbound radioactive MSH were separated by precipitation with polyethylene glycol. Synthetic $\alpha$-MSH (Sigma) was used as a standard. All samples were measured in duplicate.

\section{RESULTS}

Effects of serotonin and acetylcholine. Serotonin in concentrations ranging from $10^{-9}$ to $10^{-5} M$ was unable to alter basal MSH secretion in lobes from black- or white-adapted animals. Figure $1 \mathrm{~b}$ shows the results from superfusion experiments whereby $10^{-8}, 10^{-6}$, and $10^{-5} M$ of serotonin were tested. Similarly, basal secretion was unaffected by acetylcholine in concentrations ranging from $10^{-9}$ to $10^{-5}$ $M$ (Fig. 1a).

Involvement of $\alpha$-adrenergic and $\beta$-adrenergic receptor mechanisms. The two neurotransmitters adrenaline and noradrenaline exhibited a dose-dependent inhibitory effect on secretion of immunoassayable $\alpha-\mathrm{MSH}$ (Fig. 2a and Table 1). Effective concentrations ranged from $10^{-7}$ to $10^{-5} M$ (Table 1). The lobes were slightly more sensitive to adrenaline than to noradrenaline. The inhibition of MSH secretion induced by adrenaline or by noradrenaline, both applied at a concentration of $10^{-6} M$, was not affected by the $\alpha$-adrenergic receptor antagonist phentolamine (Figs. 2c 

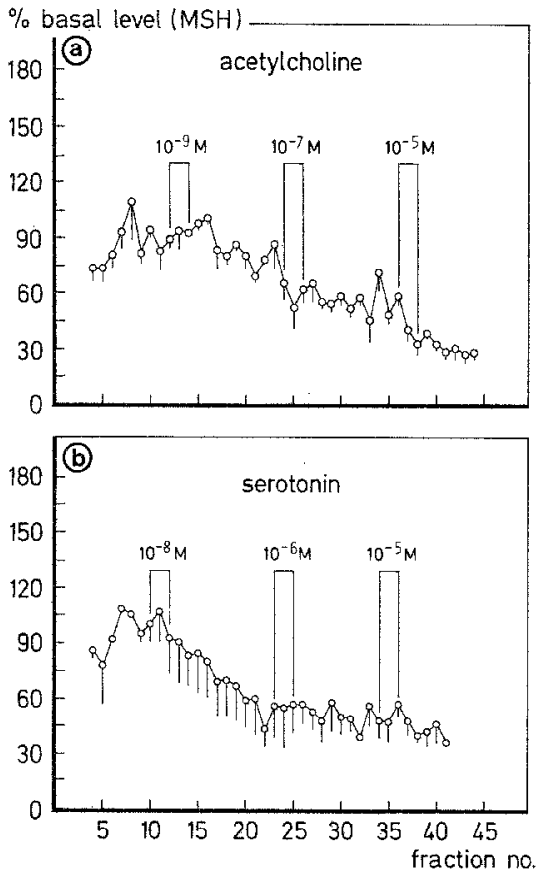

FIG. 1. Effects of acetylcholine and serotonin on MSH secretion from supcrfuscd ncurointermediate lobes of black-background-adapted Xenopus laevis. In each experiment 7.5-min superfusion fractions were collected; secretagogues were given during three 15min periods at the concentrations indicated. (a) Acetylcholine results show the mean of four individual experiments where $100 \%$ basal release for each lobe was $716,880,864$, and $652 \mathrm{pg}$ MSH/fraction. (b) Serotonin results show the mean of two individual experiments where $100 \%$ basal release for each lobe was 548 and $1160 \mathrm{pg} \mathrm{MSH} /$ fraction. Bars represent -SEM.

and $d)$ nor by the $\beta$-adrenergic receptor antagonist propranolol (Fig. 2b). Both antagonists were tested in concentrations of up to $10^{-4} M$. When adrenaline was, however, used in concentrations of $10^{-7} \mathrm{M}$, we observed a partial blockage of the inhibition by phentolamine (Table 2). The inhibitory effect on secretion induced by $10^{-6} M$ adrenaline or $10^{-6} \mathrm{M}$ noradrenaline could be blocked by the dopamine D-2 receptor antagonist sulpiride (Figs. 2e and f). The $\alpha$ adrenergic agonist phenylephrine inhibited. secretion when used at high concentrations of $10^{-5} M$ (Table 1). The inhibition of MSH secretion induced by $2 \times 10^{-5} M$ of phenylephrine was to a great extent antagonized by the administration of $10^{-4} M$ of phentol. amine (Fig. 3).

In neurointermediate lobes of blackadapted animals, the $\beta$-adrenergic receptor agonist isoproterenol appeared to be un able to alter the basal level of MSH secretion when added in low concentrations of $10^{-10}-10^{-7} M$. At high concentrations $\left(10^{-5} \mathrm{M}\right)$, the effect of isoproterenol on MSH secretion is clearly inhibitory (Fig. 4a). This inhibitory effect on melanotropin secretion could not be blocked with propranolol (Fig. 4c). Both sulpiride and phentolamine were, however, able to block the isoproterenol-induced inhibition (Fig. 4d and Table 2). An experiment with isoproterenol, but with lobes from white-adapted animals, did not show any stimulatory effect for this substance (Fig. 4b). Moreover, in an experiment with lobes from blackadapted animals that were maintained continuously under submaximum inhibition by dopamine $\left(10^{-6} \mathrm{M}\right)$, isoproterenol again failed to induce stimulation of release. Also, we could not demonstrate any stimulation with isoproterenol in experiments that were conducted with the incubation medium at pH 6.8. Hadley et al. (1976) have reported that in Rana, lowering the $\mathrm{pH}$ of the incubation medium reduced basal levels of melanotropin secretion, thus increasing sensitivity in detecting stimulatory effects on secretion. In Xenopus we found no reduction in basal secretion after lowering the $\mathrm{pH}$ from 7.38 to 6.80 .

Effects of cyclic-AMP. Lobes originating from animals adapted to a black background appeared to be insensitive to $8-\mathrm{Br}$ cyclic-AMP (Fig. 5a). Additional experiments, where 8-Br-cyclic-AMP was given for 50 -min periods, also showed no effect of this substance on MSH release. In comparison to lobes from black-adapted animals, lobes from white-adapted animals showed considerably more variation in their baseline pattern of MSH release, which generally tended to decline much more rapidly. Figures $5 b$, c, and give re- 

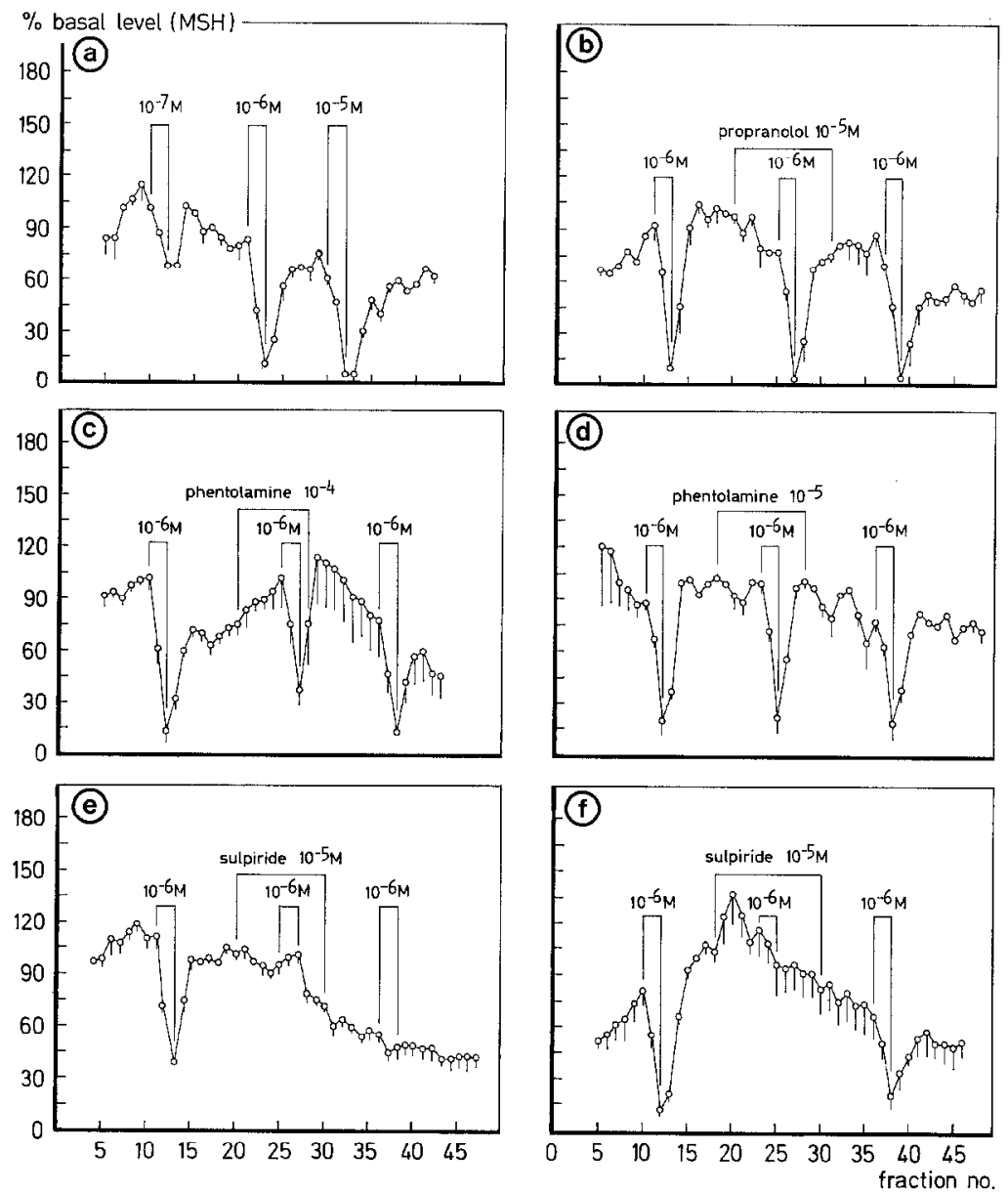

FIG. 2. Effects of noradrenaline, adrenaline, and receptor antagonists (propranolol, $\beta$-adrenergic receptor antagonist; phentolamine, $\alpha$-adrenergic receptor antagonist; sulpiride, dopamine D-2 receptor antagonist) on MSH secretion from superfused neurointermediate lobes of black-backgroundadapted Xenopus laevis. In each experiment noradrenaline or adrenaline was given during three 15min periods; administration of the receptor antagonist was started several fractions before the second pulse of noradrenaline or adrenaline and continued for several fractions after this pulse, as indicated in the figure. All graphs represent the mean of two to four experiments and the bars represent -SEM. Basal levels of release for the individual lobes within each experiment were (a) noradrenaline, 1344 and $3060 \mathrm{pg} \mathrm{MSH/fraction;} \mathrm{(b)} \mathrm{noradrenaline/propranolol,} 770$ and $1888 \mathrm{pg}$ MSH/fraction; (c) noradrenaline/phentolamine, 1464, 1756, 2120, and $2948 \mathrm{pg} \mathrm{MSH} /$ fraction; (d) adrenaline/phentolamine, 1000,1512 , and $756 \mathrm{pg} \mathrm{MSH} /$ fraction; (e) noradrenaline/sulpiride, $1552,2360,2928$, and $1640 \mathrm{pg} \mathrm{MSH} /$ fraction; and (f) adrenaline/sulpiride, 276 and $1560 \mathrm{pg} \mathrm{MSH/fraction.}$

sults of neurointermediate lobes of whiteadapted animals, where lobes with similar baseline patterns of release were grouped together and averaged. Cyclic-AMP gave a dramatic increase in $\mathrm{MSH}$ release, but establishing clear dose-response rclationships was difficult.

\section{DISCUSSION}

Previous studies have shown that the physiological state of the neurointermediate lobe tissue remains viable during a $6-\mathrm{h}$ superfusion period (Martens et al., 1981; Verburg-van Kemenade et al., 1986). Following in vitro superfusion we have found 
TABLE 1

DOSE-RESPONSE RELATIONSHIP FOR THE INHIBITION OF MSH SECRETION FROM SUPERFUSED NEUROINTERMEDIATE LOBES of Xenopus laevis BY ADRENALINE AND NORADRENALINE AND bY THE ADRENERGIC RECEPTOR AGONISTS ISOPROTERENOL ( $\beta$-RECEPTOR) AND PHENYLEPHRINE ( $\alpha$-RECEPTOR)

\begin{tabular}{lccccc}
\hline & \multicolumn{5}{c}{ \% Inhibition of MSH secretion } \\
\cline { 2 - 6 } & $10^{-9} M$ & $10^{-8} M$ & $10^{-7} M$ & $10^{-6} M$ & $10^{-5} M$ \\
\hline Noradrenaline & $0(2)$ & $0(2)$ & $32 \pm 5.8(5)$ & $83 \pm 3.3(20)$ & $100 \pm 0.0(2)$ \\
Adrenaline & $0(2)$ & $0(2)$ & $68 \pm 5.5(11)$ & $86 \pm 2.6(19)$ & $100 \pm 1.0(5)$ \\
Isoproterenol & $0(2)$ & $0(2)$ & $0(3)$ & $28 \pm 1.4(2)$ & $66 \pm 4.4(23)$ \\
Phenylephrine & $0(2)$ & $0(2)$ & $0(2)$ & $0(2)$ & $68 \pm 3.5(2)$ \\
\hline
\end{tabular}

Note. Secretagogues were added during 15 -min periods to superfused lobes; 7.5 -min fractions were collectcd and the amount of MSH in each fraction determined with a radioimmunoassay. Average value of MSH in the three fractions before addition of secretagogue was defined as basal level and the decrease in MSH value observed for the second 7.5-min fraction of secretagogue addition was expressed as a percentage of the basal value. Percentage inhibition is given \pm SEM and the numbers in parentheses indicate the number of independent determinations for each concentration of secretagogue tested.

that biosynthesis and release of pro-opiomelanocortin-related peptides are essentially normal, and that the ultrastructure of the tissue compared favorably to freshly dissected tissue (unpublished results).

Biochemical (Loh and Gainer, 1977; Martens et al., 1982) and morphological studies (Jenks et al., 1977; Weatherhead and Whur, 1972) have shown that the cells of the pars intermedia of black-background-adapted toads are extremely active in biosynthesis and release of melanotropins. In contrast, white-backgroundadapted animals have low biosynthetic rates in these cells (Jenks et al., 1977) and, in vivo, release of melanotropins is under tonic inhibition. During in vitro superfusion, neurointermediate lobes from blackbackground-adapted animals gave relatively stable baselines of MSH release, while lobes from white-backgroundadapted animals tended to give declining

TABLE 2

SUMMARY OF THE EFFECTS OF SPECIFIC RECEPTOR ANTAGONISTS ON SECRETAGOGUE-INDUCED INHIBTTION of MSH RELEASE FROM SUPERFUSEd NEURONNTERMEDIATE LOBES OF Xenopus laevis.

\begin{tabular}{lcccc}
\hline \multicolumn{1}{c}{ Secretagogues } & \multicolumn{3}{c}{ Antagonists } \\
\cline { 2 - 4 } & $\begin{array}{c}\text { Propranolol } \\
(\beta \text {-receptor })\end{array}$ & $\begin{array}{c}\text { Phentolamine } \\
(\alpha \text {-receptor })\end{array}$ & $\begin{array}{c}\text { Sulpiride } \\
(\mathrm{D}-2 \text { receptor })\end{array}$ \\
\hline Adrenaline $\left(10^{-7} M\right)$ & n.d. & \pm & n.d. \\
Adrenaline $\left(10^{-6} M\right)$ & - & - & + \\
Noradrenaline $\left(10^{-6} M\right)$ & - & + & + \\
Isoproterenol $\left(10^{-5} M\right)$ & n.d. & + & n.d. \\
Phenylephrine $\left(2 \times 10^{-5} M\right)$ & & + & \\
\hline
\end{tabular}

Note. Each secretagogue was administered during a $15-\min$ period to superfused lobes and the percentage inhibition of MSH secretion determined as described in Table 1. Administration of receptor antagonists (receptor specificity indicated in parentheses) was started several fractions before a second 15 -min pulse of secretagogue and continued for several fractions after this pulse. Inhibition of release by the secretagogue during this second pulse was compared to that obtained during the first pulse. Symbols: $(+)$ complete or almost complete antagonism of inhibitory effect of secretagogue; $( \pm$ ) partial antagonism of inhibitory effect of secretagogue; $(-)$ no detectable antagonism of secretagogue; n.d., not determined. 


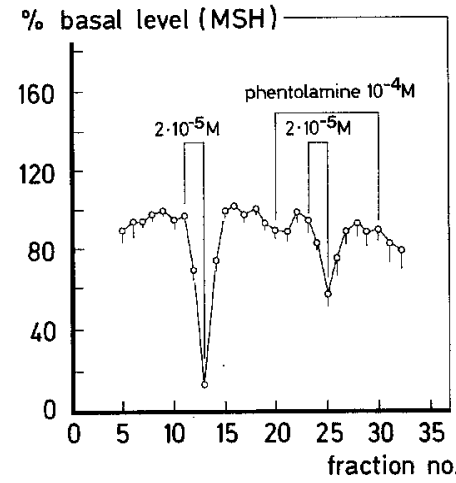

FIG. 3. Effect of $\alpha$-adrenergic receptor agonist phenylephrine and $\alpha$-adrenergic receptor antagonist phentolamine on MSH secretion from superfused neurointermediate lobes of black-background-adapted Xenopus laevis. Phenylephrine $\left(2 \times 10^{-5} M\right)$ was added during two 15-min periods; phentolamine administration was started several fractions before the second pulse of phenylephrine and continued for several fractions after this pulse, as indicated in the figure. Figure represents the mean of four expcriments. Bars represent - SEM and basal levels of release from the individual lobes were $1816,3024,2648$, and $2008 \mathrm{pg} \mathrm{MSH/fraction.}$

baselines. In our opinion this latter observation is indicative of hormone depletion and reflects the low biosynthetic capacity of the melanotropes of white-adapted animals. In lobes of black-adapted animals the high level of hormone production can apparently maintain a high rate of in vitro release.

The results of our superfusion experiments clearly show that the indolamine serotonin has no effect on the rate of MSH release from the pars intermedia of either white- or black-background adapted Xenopus. Immunocytochemically, we have found that in $X$. laevis, serotonergic fibers are restricted to the neural lobe, and no evidence for the presence of serotonin in the pars intermedia was found (unpublished results). Thus it would seem unlikely that serotonin plays a direct role in the regulation of peptide release from the pars intermedia of Xenopus. In this respect, there could be species differences in the regulation of melanotropin release. Thornton and Gesch- wind (1975) found a dose-dependent potent stimulation of $\mathrm{MSH}$ release in the lizard Anolis carolensis. Ueda et al. (1984) and Kondo et al. (1983) demonstrated the presence of serotonergic fibers in the pars intermedia of Rana catesbeiana. That serotonergic innervation of the pars intermedia might be restricted to lower vertebrate species is suggested by the studies of Kondo and coworkers, who showed that the pars intermedia of the rat, hamster, and dog were serotonin negative.

Electron microscopic studies have indicated the existence of cholinergic axon vesicles in the pars intermedia of Rana (Nakai and Gorbman, 1969) and the neurotransmitter acetylcholine has been shown to stimulate MSH secretion (Davis and Hadley, 1978). Hopkins (1971), in characterizing neurons of the pars intermedia of $X$. laevis, concluded that cholinergic innervation is absent from the intermediate lobe of this species. The results of our superfusion studies, showing that acetylcholine has no influcnce on MSH sccretion, are in agreement with Hopkins' conclusion that acetylcholine has no role, at the level of the Xenopus pars intermedia, in regulating melanotropin release.

The observation that both adrenaline and noradrenaline were very effective in inducing inhibition of MSH release in a dosedependent manner suggests the involvement of an $\alpha$-adrenergic receptor mechanism. This suggestion is supported by the fact that the $\alpha$-adrenergic receptor agonist phenylephrine inhibited hormone release, a response that could be antagonized by phentolamine. However, high concentrations of phenylephrine were needed and in antagonizing the adrenaline- and noradrenaline-induced inhibition of secretion, the dopamine D-2 receptor antagonist sulpiride proved to be much more potent than the $\alpha$ adrenergic receptor antagonist phentolaminc. This indicates that, in vitro at least, adrenaline and noradrenaline inhibit MSH release primarily through a dopamine re- 

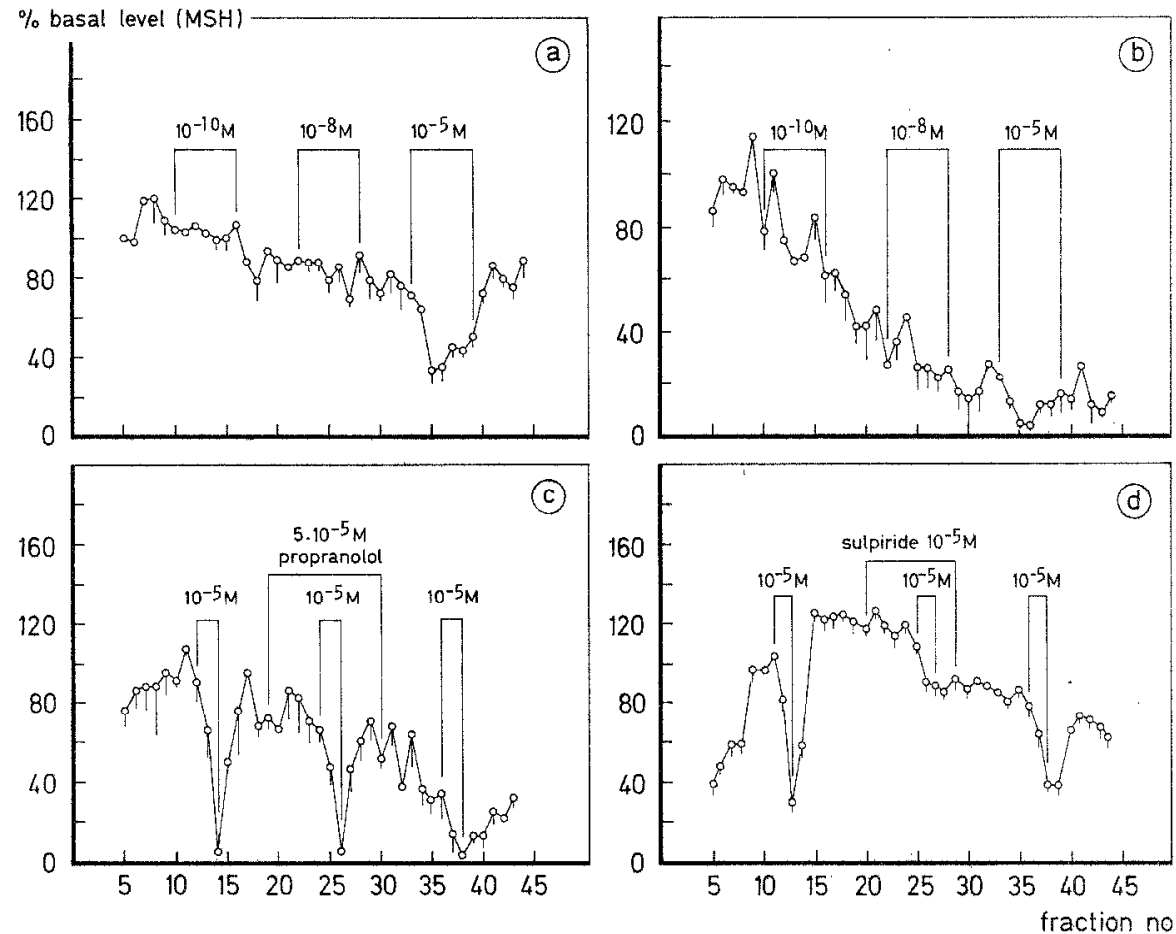

FIG. 4. Effect of $\beta$-adrenergic receptor antagonist isoproterenol on MSH secretion from superfused neurointermediate lobes of black-background-adapted Xenopus laevis. (a) Effect on secretion from lobes of black-background-adapted animals; (b) effect on secretion from lobes of white-backgroundadapted animals; (c) and (d) effects of $\beta$-adrenergic receptor antagonist propranolol and dopamine D-2 receptor antagonist sulpiride on isoproterenol-induced inhibition of MSH release. The concentrations of isoproterenol and receptor antagonists used are indicated in the figures. Administration of the receptor antagonist was started several fractions before the second pulse of isoproterenol and continued for several fractions after this pulse. All graphs represent the mean of at least two individual experiments and bars represent - SEM. Basal levels of release for individual lobes within each experiment were isoproterenol black, 2608 and $2312 \mathrm{pg}$ MSH/fraction; isoproterenol white, 1424 and 948 $\mathrm{pg} \mathrm{MSH/fraction;} \mathrm{isoproterenol/propranolol,} 2408$ and $872 \mathrm{pg} \mathrm{MSH} / \mathrm{fraction}$; isoproterenol/sulpiride, $1600,1128,1868$, and $1336 \mathrm{pg} \mathrm{MSH} /$ fraction.

ceptor mechanism, similar to the situation reported for the rat pars intermedia (Munemura et al., 1980). In in vitro experiments the tissue is, of necessity, flooded with potential secretagogue. In this situation adrenaline or noradrenaline can inhibit $\mathrm{MSH}$ release through activation of either abundantly available dopamine-type receptors (a manuscript concerning their characteristics is in preparation), or less abundant $\alpha$-adrenergic receptors. If in vivo, however, the neurotransmitter was to be delivered to the tissue in highly directed synapses between adrenergic nerve terminals and the melanotropes; then it cannot be excluded that an $\alpha$-adrenergic receptor mechanism plays a role in regulating the pars intermedia function.

With respect to possible $\beta$-adrenergic receptor mechanisms, we have shown that for Xenopus, low concentrations of the $\beta$. adrenergic receptor agonist isoproterenol have no effect on MSH release and that high concentrations actually inhibit release The fact that this inhibition could not be blocked by the $\beta$-receptor antagonist pro pranolol, but was blocked by sulpiride or phentolamine, indicates that it does not involve activation of a $\beta$-adrenergic receptor, and we therefore conclude that Xenopus 

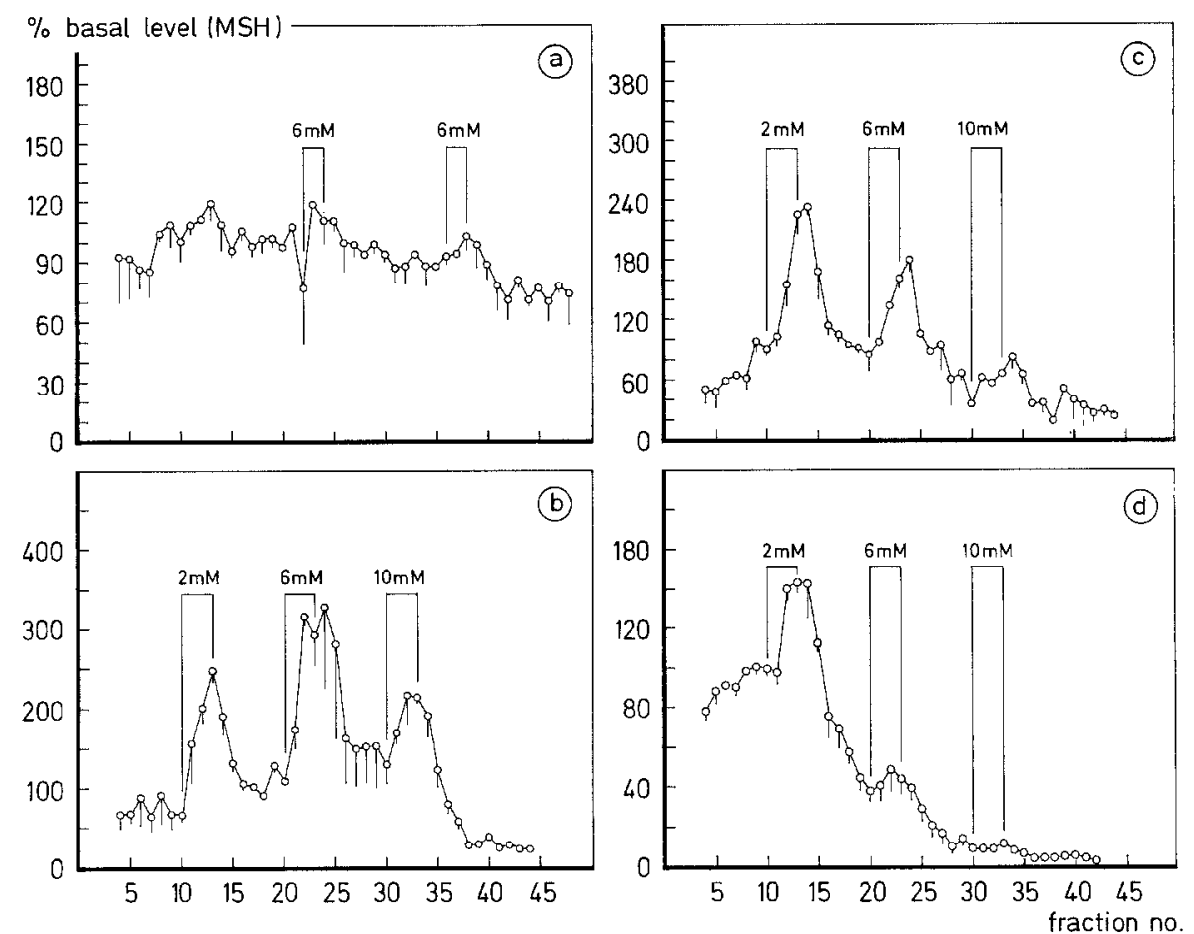

FIG. 5. Effects of 8-bromo-adenosine $3^{\prime}, 5^{\prime}$-cyclic monophosphate (cAMP) on MSH secretion from superfused neurointermediate lobes obtained from black- and white-background-adapted Xenopus laevis. The concentrations and times of cAMP administration are indicated in the figure. All graphs represent the means of at least two experiments and bars represent -SEM. Basal levels of release for the individual lobes within each experiment were (a) cAMP black, 264 and $280 \mathrm{pg}$ MSH/fraction; (b) cAMP white, 300 and 972 pg MSH/fraction; (c) cAMP white, 356 and 388 pg MSH/fraction; (d) cAMP white, 1104, 1864, and $1760 \mathrm{pg} \mathrm{MSH/fraction.}$

melanotropes are not regulated through a $\beta$-adrenergic mechanism. In contrast, it has been demonstrated for both $R$. pipiens (Bower et al., 1974) and $R$. ridibunda (Tonon et al., 1983) that a $\beta$-receptor mechanism stimulates release of MSH from the pars intermedia. It is interesting to note that with respect to the $\beta$-adrenergic receptor, a similar discrepancy between the frog and Xenopus has been reported for the receptor profile of their erythrocytes. Frog erythrocytes contain a high number of $\beta$-adrenergic receptors, whereas the erythrocytes of Xenopus lack this type of receptor (Cerione et al., 1983).

$\beta$-adrenergic receptors generally activate the adenylate cyclase system (Cote et al., 1980; Munemura et al., 1980). The lack of this receptor on MSH cells of $X$. laevis raises questions concerning the involvement of cyclic-AMP as an intracellular factor for stimulation of hormone release. In both our present experiments and those reported earlier (Jenks et al., 1977), we found a clear stimulation of MSH release, in contrast to Loh et al. (1981) who conclude from their results that cyclic-AMP inhibits release of MSH. In the present investigation the superfusion system has allowed us to follow the time course of cyclic-AMP-induced stimulation. These studies have revealed that a pulse of 8-Brcyclic-AMP is so effective in stimulating the secretory process, that in many cases the lobes became almost depleted of MSH and thus could no longer maintain release 
and were hardly sensitive to subsequent pulses of cyclic-AMP. In their studies, Loh et al. (1981) preincubated lobes of whitebackground-adapted animals for $30 \mathrm{~min}$ prior to the start of the release experiment, which proceeded for an additional $3 \mathrm{hr}$ of in vitro incubation. In the case of the cyclicAMP treated group, cyclic-AMP was present during both the preincubation and experimental periods. Possibly the pretreatment with cyclic-AMP depleted the lobes of MSH.

Our results with 8 -Br-cAMP illustrate the importance of considering responses of lobes from both white-adapted and blackadapted animals. The reason for the failure of lobes from black-adapted animals to respond, or to respond very poorly; to cyclic-AMP treatment remains to be clarified. Possibly the endogenous cyclic-AMP levels in the cells of the pars intermedia of blackadapted animals were already elevated, reflecting the physiological state of the animals prior to conducting the experiments. In that Xenopus lacks a $\beta$-adrenergic receptor, still to be resolved are questions concerning which receptor systems might be involved in activation of the adenylate cyclase system in the melanotropes of this species. In recent experiments we have found that both the neuropeptides thyrotropin-releasing hormone and corticotropin-releasing hormone show a similar phenomenon as that displayed by cyclicAMP, namely, that they stimulate release from lobes of white-adapted but not blackadapted animals (manuscript in preparation). We are investigating whether one of these neuropeptides could be an MSH release stimulating factor in $X$. laevis.

\section{ACKNOWLEDGMENTS}

We thank Dr. H. Vaudry and Dr. MC. Tonon (Rouen, France) for valuable discussion, Mr. P. M. J. M. Cruysen and Mr. R. Stoop for excellent technical assistance, Mr. R. J. C. Engels for the animal care, $\mathrm{Mr}$. Th. Oor for the illustrations, and Mrs. E. M. Jansen-Hoorweg for typing the manuscript.

\section{REFERENCES}

Bower, A., Hadley, M. E., and Hruby, V. J. (1974). Biogenic amines and control of MSH-release. Science 184, 70-72.

Cerione, R. A., Strulovici, B., Benovic, J. L., Stradler, C. D., Caron, M. G., and Lefkowitz, R. J. (1983). Reconstitution of $\beta$-adrenergic receptors into lipid vesicles: Affinity chromatography purified receptors convey catecholamine responsiveness to a heterologous adenylate $\mathrm{cy}-$ clase system. Froc. Natl. Acad. Sci. USA 80, 4899-4903.

Cote, T., Munemura, M., Eskay, R. L., and Kebabian, J, W., with technical assistance of R. Long (1980). Biochemical identification of the $\beta$-adrenoreceptor and evidence for the involvement of an adcnosinc $3^{\prime}, 5^{\prime}$-monophosphate system in the $\beta$-adrenergically induced release of $\alpha$-melanocyte-stimulating hormone in the intermediate lobe of the rat pituitary gland. Endocrinology 107 , $108-116$.

Davis, M. D., and Hadley, M. E. (1978). Pars intermedia electrical potentials: Changes in spike frequency induced by regulatory factors of melanocyte-stimulating hormone (MSH) secretion. Neuroendocrinology 26, 277-282.

Dierst-Davis, K., Ralph, C. L., and Pechersky, J. L. (1966); Effects of pharmacological agents on the hypothalamus of Rana pipiens in relation to the control of skin melanophores. Gen. Comp. Endocrinol. 6, 409-419.

Hadley, M. E., Hruby, V. J., Bower, A. (1976). Cellular mechanisms controlling melanophore stimulating hormone (MSH) release. Gen. Comp. Endocrinol. 26, 24-35.

Hogben, L., and Slome, D. (1931). The pigmentary effector system. VI. The dual character of endocrine coordination in amphibian color change. Proc. R. Soc. London Ser. B 108, 10-53.

Hopkins, C. R. (1971). Localization of adrenergic fibers in the amphibian pars internedia by electron microscopc autoradiography and their selective removal by 6-hydroxydopamine. Gen. Comp. Endocrinol. 16, 112-120.

Jackson, S., and Lowry, P. J. (1983). Secretion of proopiocortin peptides from isolated perfused rat pars intermedia cells. Neuroendocrinology 37 , $248-257$.

Jenks, B. G. (1977). Control of MSH synthesis and re lease in the aquatic toad, Xenopus laevis. Front. Horm. Res. 4, 63-65.

Jenks, B. G., van Overbeeke, A. P., and McStay, B. F. (1977). Synthesis, storage, and release of MSH in the pars intermedia of the pituitary gland. of Xenopus laevis during black adaptation. Canad. J. Zool. 55, 922-927. 
Jenks, B. G., Martens, G. J. M., van Helden, H. P. M., and van Overbeeke, A. P. (1985). Biosynthesis and release of melanotropins and related peptides by the pars intermedia in Xenopus laevis. In "Current Trends in Comparative Endocrinology" (B. Lofts and W. N. Holmes, eds.), pp. 149-153. Hong Kong Univ. Press, Hong Kong.

Kondo, Y., Nagatsu, I., Yoshida, M., Karasawa, N., and Nagatsu, T. (1983). Existence of noradrenalin cells and serotonin cells in the pituitary gland of Rana catesbeiana. Cell Tissue Res. 228, 405-408.

Loh, Y. P., and Gainer, H. (1977). Biosynthesis, processing and control of release of melanotropic peptides in the neurointermediate lobe of Xenopus laevis. J. Gen. Physiol. 70, 37-58.

Loh, Y. P. and Jenks, B. G. (1981). Evidence for two different turnover pools of adrenocorticotropin, $\alpha$-melanocyte stimulating hormone, and endorphin-related peptides by the frog pituitary neurointermediate lobe. Endocrinology 109, 54-61.

Loh, Y. P., Li, A., Gritsch, H. A., and Eskay, R. L. (1981). Immunoreactive $\alpha$-melanotropin and $\beta$ endorphin in the toad pars intermedia: Dissociation in storage, secretion and subcellular localization. Life Sci. 29, 1599-1605.

Martens, G. J. M., Jenks, B. G., and van Overbeeke, A. P. (1981). Microsuperfusion of neurointermediate lobes of Xenopus laevis: Concomitant and coordinately controlled release of newly synthesized peptides. Comp. Biochem. Physiol. C 69, $75-82$.

Martens, G. J. M., Jenks, B. G., and van Overbeeke, A. P. (1982). Biosynthesis of pairs of peptides related to melanotropin, corticotropin and endorphin in the pars intermedia of the amphibian pituitary gland. Eur. J. Biochem. 122, 1-10.

Munemura, M., Eskay, R. L., and Kebabian, J. W., with technical assistance of R. Long (1980). Release of $\alpha$-melanocyte-stimulating hormone from dispersed cells of the intermediate lobe of the rat pituitary gland: Involvement of catecholamines and adenosine $3^{\prime}, 5^{\prime}$-monophosphate. Endocrinology 106, 1795-1803.

Munemura, M., Cote, T. E., Tsuruta, K., Eskay, R. L., and Kebabian, J. W., with technical assistance of R. Long (1980). The dopamine receptor in the intermediate lobe of the rat pituitary gland:
Pharmacological characterization. Endocrinology 107, 1676-1683.

Nakai, Y., and Gorbman, A. (1969). Evidence for a doubly innervated secretory unit in the anuran pars intermedia. II. Electron microscopic studies. Gen. Comp. Endocrinol. 13, 108-116.

Terlou, M., Goos, H. J. Th., and van Oordt, P. G. W. J. (1974). Hypothalamic regulation of pars intermedia activity in amphibians. Fortschr. Zool. 22, 117-133.

Thornton, V. F., and Geschwind, I. I. (1975). Evidence that serotonin may be a melanophore-stimulating hormone releasing factor in the lizard, Arolis carolensis. Gen. Comp. Endocrinol. 26, 346-353.

Tilders, F. J. H., Post, M., Jackson, S., Lowry, P. J., and Smelik, P. G. (1981). $\beta$-adrenergic stimulation of the release of ACTH- and LPH-related peptides from the pars intermedia of the rat pituitary gland. Acta Endocrinol. 97, 343-351.

Tonon, MC, Leroux, P., Stoeckel, M. E., Jegou, S., Pelletier, G., and Vaudry, H. (1983). Catecholaminergic control of $\alpha$-melanocyte-stimulating hormone ( $\alpha$-MSH) release by frog neurointermediate lobe in vitro: Evidence for a direct stimulation of $\alpha-\mathrm{MSH}$ release by thyrotropin-releasing hormone. Endocrinology 112, 133-141.

Ueda, S., Nojyo, Y., and Sano, Y. (1984). Immunohistochemical demonstration of serotonin neuron system in the central nervous system of the bullfrog, Rana catesbeiana. Anat. Embryol. 169, 219-229.

Vaudry, H., Tonon, MC, Delarue, C., Vaillant, R., and Kraicer, J. (1978). Biological and radioimmunological evidence for melanocyte-stimulating hormone (MSH) of extrapituitary origin in the rat brain. Neuroendocrinology 27, 9-24.

Verburg-van Kemenade, B. M. L., Tappaz, M., Paut, L., and Jenks, B. G. (1986). GABAergic regulation of melanocyte-stimulating hormone secretion from the pars intermedia of Xenopus laevis: Immunocytochemical and physiological evidence. Endocrinology 118, 260-267.

Weatherhead, B., and Whur, P. (1972). Quantification of the ultrastructural changes in the "melanocyte stimulating hormone cell" of the pars intermedia of the pituitary in the amphibian Xenopus laevis after change of background color. $J$. Endocrinol. $51,521-532$. 